\title{
Regional Characteristic Analysis of Emission Intensity of the Main Pollutants in China
}

\author{
Yaling Liu ${ }^{a}$, Wenjing Zhang ${ }^{b}$, Yueying $W^{c}{ }^{c}$, Weili Ye ${ }^{d}$, Qiang Wang ${ }^{e}$ \\ ${ }^{1}$ Chinese Academy for Environmental Planning (CAEP) \\ Beijing, China \\ aliuyl@caep.org.cn
}

\begin{abstract}
Keywords: emission intensity, main pollutants, regional characteristics, industrial emission intensity.

Abstract. Emission intensity of the main pollutants could indicate the relationship between economic development and environmental load in certain regions. We collected emission data of 6 main pollutants for different provinces in 2012, including chemical oxygen demand (COD), ammonia nitrogen, sulfur dioxide, nitrogen oxide, industrial dust and industrial solid waste. And by employing analytic hierarchy weighting method, we evaluated the contamination effect for the provinces, which shows significant regional difference among provinces. Specifically, developed areas such as provinces in the eastern China have lower emission intensity while the western provinces have relatively higher emission intensity. Through a comparison to the case study in 2005 and 2012, the achievements and existing problems of pollutants emission control were clearly stated. Based on the analysis, we suggest that varies practical pollution control strategies should be adopted in different provinces, according to their pollution characteristic differences in aspects such as geography, industry, economy and so on.
\end{abstract}

\section{Introduction}

Accompanying thirty years of economy boosting and great economic achievement, China is experiencing various environmental hurdles, such as water pollution, air contamination, and ecological degradation, which endanger the living quality of ordinary people as well as the stability of the society. In order to relax the environmental and ecological pressure, and to build a resource-efficient and environment-friendly society, the government has set the grand goal of sustainable development during the 'the 12th five-year plan' ( in 2011-2015 period), and assigned a major pollutant emission control target for each province, aiming to reducing the total emissions of chemical oxygen demand (COD),sulfur dioxide $\left(\mathrm{SO}_{2}\right)$, ammonia-nitrogen, and nitrogen oxide (NOx) decreased by $8 \%, 8 \%, 10 \%$ and $10 \%$, respectively, compared with the total amount of pollutant emissions in 2010.

There was a great decrease of main pollutant emissions in China after the official implementation of total emission control. Specifically, relatively low emission intensity has already been achieved in some regions where further emission control is not necessary and difficulty. So in order to further reduce the total emission, one should turn to the regions where the total emission intensity is still high. At present, there were a few studies of regional dependents of pollutant emission intensities. Hong Luo, analyzed the relationship between economic development and emission intensity of $\mathrm{COD}, \mathrm{SO}_{2}$, and industrial dust in eastern, central, and western China, and found a stepped emission intensity pattern of three pollutants, which corresponds to the respective economic development level. Zhongkui Zhou and Jinhui Liu studied the air emission intensity in Beijing during 2001 and 2004, and concluded that emission intensity was at a low level in China compared with developed countries. Shishan Liu and Xuejun Lu, analyzed and assessed the regional differences on emission intensity of main pollutants among counties of Lianyungang city by standard variance method, and provided specific suggestions for regional pollution control. Similar method used by Dan Su et al. to study the pollutant emission intensity as well as estimated pollution potential for different sectors in Liao watershed, and also analyzed key pollution characteristics of industrial wastewater. Jianjun Liu et al. 
focused on the trends of major pollutants emission quantity and intensity in Shandong province in the period of 2001-2007, and examined the relationship between economic development and emission quantity.

In the context of great geographic, social and economic variations among provinces in China, studies aiming specifically at time series and regional characteristics of emission intensity are limited, let alone implementation of the research results in reality. Hence, based on the regional differences, studying on main pollutants emission intensity, components, pressure and characteristics for each province, as well as providing specific pollution control methods and policy implications for different provinces, are of great importance and necessity to achieve pollution control goals and facilitate the green development.

In China, the main pollutants counted includes COD, ammonia nitrogen, sulfur dioxide, NOx, industrial dust and industrial solid waste from industry and household. The total emissions of the six main pollutants were 24.347 million ton, 2.5359 million ton, 21.176 million ton, 23.378 million ton, 12.343 million ton, and 1.44 million ton in 2012, respectively, which decreased by $5.03 \%, 4.10 \%$, 3.09\%, 8.34\%, 3.4\%, and 71.1\% compared with the one in 2010. But, the differences among the provinces on total emissions both of main pollutants and industrial pollutants were significant. As showed in table 1 and 2, provinces that contributed most to the total emission emitted 10 times more pollutants compared with provinces that contributed least did. And, the regional characteristics of emission were significantly indicated, (Table $1 \&$ Table 2 ) due to the enormous differences of land area, the level of economic development, industrial structure, energy structure characteristics, pollution control level population, living standards and so on. In terms of total emissions, emissions from Shandong, Hebei, Guangdong provinces with larger area and more developed economy, were much higher than that from Qinghai and Hainan provinces. However, the regional characteristics of industrial pollutants emission is different. For instance, heavy industry oriented provinces such as Heilongjiang, Shandong, and Hebei discharged more industrial pollutants than the one in well-developed and service industry oriented provinces such as Beijing and Hainan.

Table 1 China's main pollutant emissions extreme value in 2012 (ten thousand ton)

\begin{tabular}{ccccccc}
\hline Items & COD & Ammonia & Sulfur dioxide & $\begin{array}{c}\text { Nitrogen } \\
\text { oxides }\end{array}$ & Industrial dust Industrial solid waste \\
\hline maximum & 192.12 & 2.41 & 174.88 & 176.11 & 123.59 & 43 \\
(provinces) & (Shandong) & (Guangdong) & (Shandong) & (Hebei) & (Hebei) & (Yunnan) \\
\hline minimum & 10.38 & 0.98 & 3.41 & 10.34 & 1.66 & 0 \\
(provinces) & (Qinghai) & (Qinghai) & (Hainan) & (Hainan) & (Hainan) & (others) \\
\hline
\end{tabular}

Table 2 China's main industrial pollutant emissions extreme value in 2012 (ten thousand ton)

\begin{tabular}{ccccccc}
\hline Items & COD & ammonia & $\begin{array}{c}\text { Sulfur } \\
\text { dioxide }\end{array}$ & $\begin{array}{c}\text { Nitrogen } \\
\text { oxides }\end{array}$ & Industrial dust & $\begin{array}{c}\text { Industrial solid } \\
\text { waste }\end{array}$ \\
\hline maximum & 98.20 & 2.58 & 154.38 & 123.82 & 105.57 & 43 \\
(provinces) & (Heilongjiang) & (Hunan) & (Shandong) & (Shandong) & (Hebei) & (Yunnan) \\
\hline minimum & 0.63 & 0.04 & 3.3 & 7.19 & 1.07 & 0 \\
(provinces) & (Beijing) & (Beijing) & (Hainan) & (Hainan) & (Hainan) & (others) \\
\hline
\end{tabular}

Except for total emissions of main pollutants, the emission intensity defined as pollutants emission per unit of GDP, and it is used as an index to indicate regional characteristics of pollutants emission. This index reflects the environmental burden of GDP, and also indirectly reflects the regional economy, technology and pollution control capability (Table 3). Compared with the total amount of pollutant emissions, regional difference of emission intensity extreme value is even more significant (Table 4). The provinces with high emission intensity are developing western regions with the maximum industrial pollutant emission and northeast regions where heavy industry is intensive, while provinces with low emission intensity are more developed provinces/cities, such as Beijing and Shanghai. While the emission intensity of industrial dust and industrial solid waste in Xinjiang province are largely higher than in any other regions, and even higher than national average. Thus, the level of industrial emissions largely determines the emission intensity, and it will be key point for emission control, combined with the control of household emissions. 
Table 3. 2012 China’smain pollutant emissions intensity extreme value (kg/thousand yuan GDP)

\begin{tabular}{|c|c|c|c|c|c|c|}
\hline Items & COD & ammonia & $\begin{array}{c}\text { Sulfur } \\
\text { dioxide }\end{array}$ & $\begin{array}{l}\text { Nitrogen } \\
\text { oxides }\end{array}$ & Industrial dust & $\begin{array}{c}\text { Industrial solid } \\
\text { waste } \\
\end{array}$ \\
\hline maximum & $\begin{array}{c}109.5 \\
(H o i n n g i a n g\end{array}$ & 7.88 & $\begin{array}{c}173.7 \\
\end{array}$ & 194.5 & $\begin{array}{c}92.7 \\
\text { (Xinojiano) }\end{array}$ & $\begin{array}{c}46.6 \\
\text { (Xinoiiano) }\end{array}$ \\
\hline (provinces) & (Heilongjiang) & (Hainan) & (Ningxia) & （Gansu） & (Xingjiang) & （Xingjiang） \\
\hline $\begin{array}{l}\text { minimum } \\
\text { (provinces) }\end{array}$ & $\begin{array}{c}10.4 \\
\text { (Beijing) }\end{array}$ & $\begin{array}{c}1.15 \\
\text { (Beijing) }\end{array}$ & $\begin{array}{c}5.2 \\
\text { (Beijing) }\end{array}$ & $\begin{array}{c}9.9 \\
\text { (Shanghai) }\end{array}$ & $\begin{array}{c}3.7 \\
\text { (Beijing) } \\
\end{array}$ & $\begin{array}{c}0 \\
\text { (others) }\end{array}$ \\
\hline
\end{tabular}

Table 4. 2012 China's industrial main pollutant emissions intensity extreme value (kg/thousand yuan GDP)

\begin{tabular}{|c|c|c|c|c|c|c|}
\hline Items & COD & ammonia & Sulfur dioxide & $\begin{array}{l}\text { Nitrogen } \\
\text { oxides }\end{array}$ & Industrial dust & $\begin{array}{c}\text { Industrial solid } \\
\text { waste }\end{array}$ \\
\hline $\begin{array}{l}\text { maximum } \\
\text { (provinces) }\end{array}$ & $\begin{array}{c}147.3 \\
\text { (Heilongjiang) }\end{array}$ & $\begin{array}{c}3.96 \\
\text { (Ningxia) }\end{array}$ & $\begin{array}{c}2.041 \\
\text { (Guizhou) }\end{array}$ & $\begin{array}{c}174.5 \\
\text { (Gansu) }\end{array}$ & $\begin{array}{c}100.0 \\
\text { (Xingjiang) }\end{array}$ & $\begin{array}{c}57.8 \\
\text { (Xingjiang) }\end{array}$ \\
\hline $\begin{array}{l}\text { minimum } \\
\text { (provinces) }\end{array}$ & $\begin{array}{c}1.0 \\
\text { (Beijing) }\end{array}$ & $\begin{array}{c}0.06 \\
\text { (Beijing) }\end{array}$ & $\begin{array}{c}9.6 \\
\text { (Beijing) }\end{array}$ & $\begin{array}{c}13.8 \\
\text { (Shanghai) }\end{array}$ & $\begin{array}{c}3.5 \\
\text { (Shanghai) }\end{array}$ & $\begin{array}{c}0 \\
\text { (others) }\end{array}$ \\
\hline
\end{tabular}

\section{Data and Methodology}

The data used in this study were derived from 2012 Environmental Statistical Yearbook of China, including data of the main pollutants emission such as chemical oxygen demand, ammonia, sulfur dioxide, smoke (powder) dust and industrial solid waste emissions for 30 provinces (except for Tibet) in mainland China. The statistical data of major pollutants emissions contains the total emissions and industrial emissions. In addition, Statistical data of economic development, such as Gross Domestic Product (GDP) and Gross Industrial Product (GIP), has also been collected. With the help of data presented, we calculated the provincial values of major pollutants emission intensity (kg / thousand yuan GDP) and the major pollutants in industrial activity (kg / yuan industrial output), which performed the main pollutant emission intensity and industrial emissions intensity among different regions.

In this study, pollution factors with great impact on environment will be classified into three layers: water, air and solid waste. Then judgment matrix of assessment index will be developed respectively for each index layer to conduct consistency check and calculate weights for each index in its layer. Finally, after an overall consistency check, 7 kinds of pollutant will be weighted by their environmental impacts (Table 5). After the non-dimensionalization of raw data, evaluation values of each province were calculated for integrated emission intensity and industrial emission intensity (Table 6). This value indicates pollutants emission level in a target area, that is, the higher the value, the greaterthe environmental burden caused by per unit of GDP created, and the lower the environmental efficiency, the greater the pressure to environment.

Table 5.The weight of main pollutant emissions intensity

\begin{tabular}{lllllll}
\hline & COD & Ammonia & Sulfur dioxide & Nitrogen oxides & smoke & dust \\
\hline Weights & 0.2507 & 0.376 & 0.2044 & 0.0527 & 0.0226 & 0.0936 \\
\hline
\end{tabular}

Table 6 the comprehensive evaluation of provinces main pollutant emissions intensityin 2012

\begin{tabular}{|c|c|c|c|c|c|c|c|}
\hline Province & $\begin{array}{l}\text { Integrated } \\
\text { emission } \\
\text { intensity }\end{array}$ & $\begin{array}{l}\text { Industrial } \\
\text { emission } \\
\text { intensity } \\
\text { value }\end{array}$ & sorting & Province & $\begin{array}{l}\text { Integrated } \\
\text { emission } \\
\text { intensity }\end{array}$ & $\begin{array}{l}\text { Industrial } \\
\text { emission } \\
\text { intensity } \\
\text { value }\end{array}$ & sorting \\
\hline Beijing & 0.000 & 0.000 & 1 & Hubei & 0.394 & 0.182 & 15 \\
\hline Shanghai & 0.082 & 0.008 & 2 & Sichuan & 0.420 & 0.141 & 12 \\
\hline Tianjin & 0.085 & 0.036 & 3 & Anhui & 0.438 & 0.133 & 11 \\
\hline
\end{tabular}




\begin{tabular}{llllllll}
\hline Jiangsu & 0.146 & 0.059 & 4 & Qinghai & 0.466 & 0.287 & 21 \\
Zhejiang & 0.168 & 0.065 & 6 & Guangxi & 0.469 & 0.209 & 17 \\
Guangdong & 0.225 & 0.062 & 5 & Shanxi & 0.470 & 0.227 & 18 \\
Shandong & 0.241 & 0.067 & 7 & Hunan & 0.506 & 0.434 & 27 \\
Fujian & 0.281 & 0.118 & 9 & Jiangxi & 0.515 & 0.306 & 23 \\
Shanxi & 0.330 & 0.231 & 19 & Yunnan & 0.539 & 0.290 & 22 \\
Chongqing & 0.333 & 0.142 & 13 & Hainan & 0.541 & 0.101 & 8 \\
Hebei & 0.353 & 0.157 & 14 & Guizhou & 0.598 & 0.407 & 25 \\
Liaoning & 0.353 & 0.123 & 10 & Heilongjia & 0.630 & 0.415 & 26 \\
$\begin{array}{l}\text { Henan } \\
\text { Inner }\end{array}$ & 0.376 & 0.257 & 20 & Gansu & 0.635 & 0.551 & 29 \\
mogolia & 0.377 & 0.381 & 24 & Xinjiang & 0.757 & 0.479 & 28 \\
Jilin & 0.390 & 0.189 & 16 & Ningxia & 0.849 & 0.705 & 30 \\
\hline
\end{tabular}

\section{Results}

As shown in Table 6, national average integrated emission intensity and industrial emission intensity are 0.318 and 0.143 , separately, and only 8 and 9 provinces are over national average level. In general, overall pollutants emission intensity is at a relatively low level, and rapid development in some areas cover severe pollution problems in other areas. Beijing, Tianjin and Shanghai are the top three cities of the lowest integrated and industrial emission intensity, which are only 1\%, 25\% and 26\% of national average intensity, while Ningxia province is of the highest integrated and industrial emission intensity, which are 2.67 and 4.92 times of national average. In terms of regional distribution, the top 10 cities of lowest integrated emission intensity are municipalities or eastern coastal provinces, except for Shaanxi Province; and the 5 cities of highest integrated comprehensive emission intensity are less developed western provinces, except Heilongjiang, which is a traditional conventional industrial-oriented city. Similarly, for industrial emission intensity, the top 10 cities with lowest emission intensity are also either municipalities or located in eastern coastal areas, and Heilongjiang and other western provinces are of highest emission intensity. Evaluation results mentioned above show that emission intensity indicates a strong regional difference among eastern, central and western areas, which also is in accordance with the regional difference of economic development level.

Ranking changes of both integrated emission intensity and industrial emission intensity were analyzed in this study, and the results indicate a marked change. To be specific, Hainan, Anhui and Sichuan Provinces rank higher in industrial emission intensity rather than in integrated emission intensity. While oppositely, Inner Mongolia, Henan, Hunan and Shaanxi provinces rank lower in in industrial emission intensity rather than in integrated emission intensity. Results stated above could be explained by the following facts. For Hainan, Anhui, and Sichuan Provinces, light industry and service industry are dominant, which contribute less to industrial emission intensity but indirectly lead to a large population that contribute more to integrated pollutants emission from household sector. For Inner Mongolia, Henan, Hunan and Shaanxi provinces, industrial pollutants emission is the major contributor to environment contamination resulted from their industrial structure and outdated technology, thus control of industrial emission, rather than household emission, is of high priority.

\section{Discussion}

\section{Comparison study}

Chen Dongjing calculated major pollutants emission intensity in 2005(some pollutants are not included in statistics of 2005, so the statistical data used in this study are included both in 2005 and 2012), and conducted the relevant ranking as Table 7 and 8 reports. 
Table 7 the maximum and the minimum of main pollutant emissions in 2005 (ten thousand tons)

\begin{tabular}{|c|c|c|c|c|c|}
\hline Items & COD & ammonia & Sulfurdioxide & $\begin{array}{l}\text { Soot } \\
\text { smoke }\end{array}$ & Dust \\
\hline $\begin{array}{l}\text { maximum } \\
\text { (provinces) }\end{array}$ & $\begin{array}{l}107.0 \\
\text { (Guangxi) }\end{array}$ & $\begin{array}{l}10.4 \\
\text { (Henan) }\end{array}$ & $\begin{array}{l}200.3 \\
\text { (Shandong) }\end{array}$ & $\begin{array}{l}112.2 \\
\text { (Shanxi) }\end{array}$ & $\begin{array}{l}604.7 \\
\text { (Shanxi) }\end{array}$ \\
\hline $\begin{array}{l}\text { minimum } \\
\text { (provinces) }\end{array}$ & $\begin{array}{l}7.2 \\
\text { (Qinghai) }\end{array}$ & $\begin{array}{l}0.7 \\
\text { (Qinghai) }\end{array}$ & $\begin{array}{l}2.2 \\
\text { (Hainan) }\end{array}$ & $\begin{array}{l}1.1 \\
\text { (Hainan) }\end{array}$ & $\begin{array}{l}0.004 \\
\text { (Tianjin) }\end{array}$ \\
\hline
\end{tabular}

Table 8 the main pollutant emissions intensity extremumin 2005 (kg/ten thousand yuan GDP)

\begin{tabular}{|c|c|c|c|c|c|}
\hline Items & COD & ammonia & Sulfur dioxide & $\begin{array}{l}\begin{array}{l}\text { Soot } \\
\text { smoke }\end{array} \\
\end{array}$ & Dust \\
\hline $\begin{array}{l}\text { maximum } \\
\text { (provinces) }\end{array}$ & $\begin{array}{l}26.3 \\
\text { (Guangxi) }\end{array}$ & $\begin{array}{l}2.8 \\
\text { (Ningxia) }\end{array}$ & $\begin{array}{l}69.9 \\
\text { (Guizhou) }\end{array}$ & $\begin{array}{l}27.2 \\
\text { (Shanxi) }\end{array}$ & $\begin{array}{l}146.7 \\
\text { (Shanxi) }\end{array}$ \\
\hline $\begin{array}{l}\text { minimum } \\
\text { (provinces) }\end{array}$ & $\begin{array}{l}1.7 \\
\text { (Beijing) }\end{array}$ & $\begin{array}{l}2.0 \\
\text { (Beijng) }\end{array}$ & $\begin{array}{l}2.5 \\
\text { (Hainan) }\end{array}$ & $\begin{array}{l}0.9 \\
\text { (Beijing) }\end{array}$ & $\begin{array}{l}0.0003 \\
\text { (Jiangsu) }\end{array}$ \\
\hline
\end{tabular}

By comparison with the 2012 data, maximum total emissions of major pollutants in 2005, except for chemical oxygen demand, have obviously decreased at different level;in particular, industrial solid waste emission has decreased most.Provinces with maximum total emissions have shiftedfrom Shandong, Guangdong, Hebei and Yunnan to Guangxi, Henan, Shandong and Shanxi. Minimum total emissions compared to 2005 also have marked decrease, but provinces of minimum total emissions have barely changed, which are Qinghai, Hainan and provinces with less developed industrial economy, smaller area.

A great improvement of pollutants emission situation has been observed in these years. In 2012, the extreme values of integrated emission intensity and industrial emissions intensity, especially for ammonia-nitrogen and $\mathrm{SO}_{2}$, were decreased to $25 \%-40 \%$ and $20 \%-60 \%$ of that of 2005 , respectively. In addition, industrial solid waste emissions in certain provinces have even reduced to zero. Provinces with the highest emission intensity have shifted from the industry dominated regions to the less developed western regions. Meanwhile, provinces with the lowest intensity have shifted from Qinghai and Hainanto developed regions like Beijing and Shanghai.

\section{Watershed water quality and emission intensity analysis}

Based on the evaluationof integrated emission intensity for each province, water quality data in 2012 national assessment for each key watershed state-controlled sections were organized and ranked in this study as indicated in Table 9.

Based on the comparison of the water quality and integrated emission intensity, provinces can be classified into three categories. The first category, including Ningxia, Jiangxi, Gansu, Hunan and Guizhou provinces, represents a positive ranking of water quality instead of integrated emission intensity. Although these regions preserve a relatively good water quality right now, there still exist potential threat to the water because of their high emission intensity. It implies that the industry development over the five provinces is still in its infancy with the outdated technology, while the relatively small overall scale promotes no exceed of environment capacity. Therefore source control is crucial to maintain the precious water in good quality in these provinces.

The second category, including Hebei, Jilin, Shaanxi, Tianjin, Shanghai and Beijing describes a positive ranking of integrated emission intensity rather than water quality. This could be explained partially by their downstream locations that might be largely influenced by upstream pollution, and by their development process in which pollutants discharged had great impact on water environment and even contaminated surrounding water, even though they have already achieved a high economic development level and advanced technology. Hence, in order to promote the restoration of water quality and to balance economy and environment benefits, with the principle of no new debts, more for old debts, water pollution control is the priority for those regions.

The third category, including Henan, Sichuan, Shanxi and other 14 provinces, shows an approximate ranking of integrated emission intensity rather than water quality. It indicates that these provinces are in a crucial period of industrial restructuring and environmental characteristics changing.Thus, for these areas, opportunities should be seized to change the conventional idea of control after pollution, optimize the regional emission intensity, reduce emissions, and avoid the 
deterioration of environmental quality; at the same time, promoting pollution control technology to enhance and accelerate water environment restoration would lead to a sustainable and harmonious development.

\section{Conclusions}

There were significant regional differences in both integrated emission intensity and industry emission intensity of six major pollutants (Chemical Oxygen Demand, ammonia-nitrogen, sulfur dioxide, nitrogen oxides, smoke and dust, and industrial solid waste) in 2012. Only about one-third of the province whose emission intensity was less than national average, while those provinces with relatively developed economy and lower emission intensity lowered the national average that resulted in the fact of overall high emission intensity was veiled.

As evaluated results report, provinces with less integrated emission intensity are mostly located in the economically developed eastern coastal provinces and municipalities, while provinces with more integrated emission intensity are mostly located in the western underdeveloped areas as well as in traditional heavy industry dominated regions. Because of population and economic structure, the national ranking of industrial emission intensity is superior to the integrated emission intensity ranking in Hainan, Anhui and Sichuan Province. Due to the poor industrial structure and outdated technology, integrated emission intensity ranking is better than industrial emissions intensity ranking in Inner Mongolia, Henan, Shaanxi, Hunan Province.

Compared to 2005, the major pollutants emissions in China have been greatly improved.With the exception of chemical oxygen demand, the emission intensities of other pollutants have decreased with certain extent, especially for obvious decreasing in minimum value. Ammonia and industrial solid waste emissions and intensities have decreased most significantly among other pollutants.

\section{References:}

[1]Chen Dongjin. The space - regional differences of China's main pollutants emissions intensity analysis.[J] ecological 2008,17 (1):133-137

[2]Liu Jianjun, Liu Yanjun, Zhou Changhui. The analysis of main pollutants emission intensity in Shandong province during the 2001 and 2007[J]. Environment science and management,2010,35(7): 38 40

[3]Liu Shishan, Lu Xuejun. The differences of industrial main pollutants emission intensity in LianYungangprovince[J]. Manager Journal, 2013.12: 89 90

[4]Luohong, Wang Jinnan, Ge Chazhong. The comparison of industrial pollution and economical development in East and West of China[J]. Shanghai environment and science, 2001, 20(7): 341 346

[5]State Environmental Protection Administration of China. Environment Statistical Yearbook 2012 [R]. Beijing: China Environmental Press, 2012

[6]Sudan, Wang Zhijiang, Wangtong. The unit variance analysis of Liaohe River industrial wastewater main pollutants emission intensity.[J]. Ecological environment,2010, 19(2): 275-280

[7] Sun Juan, WuYueying, WenYuli. The countermeasures studies of main water pollutant emissions during "Twelve Five" period in Beijing.[J] Environmental Pollution \& Control,2011,33 (1): 102 $-104$

[8] Ye Weili, Wuyue Ying, Zhang Xiaonan.Emission Tradingunder the pollutants total control during "Twelve Five" period[J].environmenteconomic, 2012, (8): 36-38

[9]Zhou Zhongkui, Liu Jinhui. Atmospheric pollutants condition analysis and countermeasures study in Beijing[J]. Sichuan environment,2007,26(2): 118 121 